\title{
DIRETRIZES PARA UMA METODOLOGIA DE MODELAGEM DA INFORMAÇÃO NA CÂMARA DOS DEPUTADOS
}

\section{DIRECTRICES PARA UNA METODOLOGÍA PARA MODELADO DE LA INFORMACIÓN}

\begin{abstract}
Débora Andrade Cavalcanti - debora.and.cavalcanti@gmail.com Graduada em Engenharia Elétrica pela Universidade de Brasília (UNB).

Especialista em Arquitetura e Organização da Informação pela Universidade de Minas Gerais (UFMG). Servidora da Câmara dos

Deputados.

Mônica Erichsen Nassif - menassif89@gmail.com Doutora em Ciência da Informação pela Universidade Federal de Minas Gerais (UFMG). Docente da Escola de Ciência da Informação da UFMG.
\end{abstract}

RESUMO

Introdução: Estabelece diretrizes para a elaboração de uma metodologia para modelagem da informação na Câmara dos Deputados, com base na análise teórica dos elementos que compõem uma arquitetura da informação e dos princípios de organização da informação, organização do conhecimento e gestão da informação.

Objetivo: Possibilitar a integração, o compartilhamento e a organização da informação, contribuindo de forma efetiva para a implantação de um modelo de arquitetura da informação na Câmara dos Deputados.

Metodologia: Revisão de literatura e pesquisa documental.

Resultados: Apresenta as diretrizes para modelagem da informação, aplicadas às necessidades e práticas informacionais da Câmara dos Deputados.

Conclusões: A organização da informação está diretamente relacionada com a representação da informação, que consiste no objeto da modelagem da informação; que as diretrizes propostas neste trabalho representam um meio para a implantação de uma arquitetura da informação na Câmara dos Deputados.

Palavras-chave: Arquitetura da Informação; Organização da Informação; Organização do Conhecimento; Gestão da informação; Modelagem da informação. 


\section{INTRODUÇÃO}

A evolução da Tecnologia da Informação e Comunicação (TIC) ocorrida nas últimas décadas facilitou significativamente 0 armazenamento e 0 acesso à informação nas organizações, gerando novos processos de comunicação e de interação organizacionais. No entanto,

o contraste entre os investimentos maciços em tecnologia da informação, seu evidente potencial transformador, e os lucros auferidos contribuíram para uma percepção crescente entre as organizações de que é preciso reexaminar muitos de seus pressupostos fundamentais quanto à estruturação e uso da informação e de sua tecnologia. (MCGEE; PRUSAK, 1994, p. 6).

Segundo os mesmos autores, não é a tecnologia, mas sim a informação que fornece o maior potencial de retorno às organizações, possibilitando a criação de novos produtos e serviços e aperfeiçoando a qualidade e o processo decisório em toda a organização.

A Câmara dos Deputados (CD), embora já tenha apresentado avanços na transparência e na disseminação de suas informações, especialmente por meio da divulgação em seu Portal de informações relacionadas aos deputados, ao processo legislativo e à sua gestão, carece de ações efetivas para que a informação consumida e produzida ao longo de seus processos de trabalho se torne um ativo organizacional, servindo não somente como suporte para o desempenho de suas atividades, mas também contribuindo de forma eficiente para a tomada de decisão. Do ponto de vista do atendimento à sociedade, com a entrada em vigor da Lei no 12.527, de 18 de novembro de 2011 - Lei de Acesso à Informação (LAI), essa preocupação tornou-se ainda maior uma vez que os esforços para a organização e gestão da informação passaram a representar também uma questão de conformidade legal.

A informação legislativa, em especial, gerada no exercício das funções estabelecidas pela Constituição Federal de 1988, no Título IV - Organização dos Poderes, Capítulo I - Do Poder Legislativo, representa o principal produto da Câmara dos Deputados. A gestão dessa informação é regulada por normas específicas voltadas para a gestão do ciclo de vida dos documentos produzidos ao longo dos processos de trabalho, em suportes e formatos convencionais. Entre 
essas normas, pode-se citar a Lei no 8.159, de 8 de janeiro de 1991, além de resoluções e atos da mesa que tratam os procedimentos específicos para gestão documental na Câmara dos Deputados, os quais estão relacionados no relatório de atividades elaborado pelo Prolegis ${ }^{1}$, intitulado "Uma abordagem sobre a gestão da informação para o desenvolvimento do N-Sileg". Tais normas, no entanto, não abarcam os aspectos da gestão da informação em todos os suportes e formados nos quais é produzida atualmente, tais como áudio, vídeo e formatos digitais de produção documental. Mesmo as normas mais recentes, oriundas do programa estratégico de Gestão da Informação e do Conhecimento (PGIC), criado em março de 2010, ainda não são efetivas do ponto de vista operacional, pois estabelecem regras de caráter geral para gerir a informação.

Somado a essas questões, ao longo dos últimos quinze anos, conforme concluído pelo mesmo relatório elaborado pelo Prolegis, o aumento da produção de informação, especialmente no formato digital, a necessidade de manipulá-la de uma forma mais rápida e eficaz e a demanda por torná-la acessível por meio da internet levaram a CD a adotar, de forma intensiva, soluções de TIC. Essa adoção ocorreu, em parte, de forma isolada, com o objetivo de suprir as necessidades de registro de dados e de documentos de áreas funcionais. Mesmo com o desenvolvimento de sistemas corporativos, tais como o Sistema de Informações Legislativas - SILEG, observa-se que não foram abarcados todos os fluxos de trabalho dos órgãos usuários do sistema, fato que obrigou tais órgãos a manterem e/ou criarem bases de dados locais para o completo registro e recuperação de suas informações, na maioria das vezes com estruturas de dados diferentes do modelo corporativo e com pouca ou nenhuma interoperabilidade entre os sistemas.

Como resultado, não é raro que uma mesma informação esteja disponível em sistemas diferentes, não integrados entre si, ocasionando problemas de redundância não planejada e de inconsistência. Em muitos casos, dados são redigitados por serem originários de atividades realizadas em outras áreas, ficando sujeitos a erros ou defasagem no registro. Todos esses fatores, além de serem onerosos aos processos de trabalho e à infraestrutura tecnológica, refletem negativamente na confiabilidade da informação, seja para atender à sociedade, seja para a execução das atividades da instituição ou para a tomada de decisão.

\footnotetext{
${ }^{1}$ Prolegis - Programa de Informatização da Atividade Legislativa, instituído pela Portaria $n^{\circ}$ 80, de 29 de junho de 2006, disponível em: <http://www2.camara.leg.br/legin/int/portar/2006/portaria-80-29junho-2006-544288-norma-cd-dg.html >. Acesso em: 3 de outubro de 2012.
} 
Organizar e integrar essas informações consiste, portanto, em um desafio para a Câmara dos Deputados. Nesse contexto, foi estabelecido o projeto de Arquitetura da Informação (AI). Criado em abril de 2012 dentro do escopo do PGIC, este projeto tem como objetivo:

\begin{abstract}
Estabelecer um modelo para a organização das informações corporativas que permita a integração de seus repositórios e dos fluxos de informação, e que possibilite a adoção de mecanismos de governança eficazes para a gestão da informação institucional, desde a sua produção até a sua utilização. (BRASIL. Câmara dos Deputados. Intranet-Gestão Estratégica) ${ }^{2}$.
\end{abstract}

Além da visão arquitetural dos domínios de informação da CD e de seus relacionamentos, o projeto pretende propor uma metodologia que possibilite a implantação efetiva da arquitetura na instituição.

Este estudo buscou, portanto, propor diretrizes para a elaboração dessa metodologia, aqui denominada Modelagem da Informação. As diretrizes foram propostas com base na análise teórica elementos que compõem uma arquitetura da informação e da forma como implantá-los em uma organização, aplicados às práticas informacionais da CD. O intuito é organizar e integrar as informações da Câmara dos Deputados, possibilitando o uso eficaz dessas informações pela instituição e a implantação de um modelo de arquitetura da informação.

\title{
2. REVISÃO DE LITERATURA
}

\subsection{Arquitetura da Informação}

A preocupação humana com a organização da informação existe há vários séculos. Com o fenômeno da explosão informacional que se seguiu à Segunda Guerra Mundial, notadamente a partir do surgimento da Web, essa preocupação tornou-se ainda mais intensa.

De acordo com Bräscher e Café (2008), o objetivo da organização da informação é possibilitar o acesso ao conhecimento contido na informação. As autoras definem a organização da informação como:

\footnotetext{
${ }^{2}$ Disponível em: <https://camaranet.camara.gov.br/web/gestao-estrategica/programa-gestao-dainformacao-e-do-conhecimento> Acesso em: 10 de outubro de 2012.
} 
um processo que envolve a descrição física e de conteúdo dos objetos informacionais. O produto desse processo descritivo é a representação da informação, entendida como um conjunto de elementos descritivos que representam os atributos de um objeto informacional específico. (BRÄSCHER; CAFÉ, 2008).

O termo 'Arquitetura da Informação' surgiu no contexto na explosão informacional, tendo sido utilizado pela primeira vez pelo arquiteto Richard Saul Wurman, em 1976, com a seguinte definição: "a ciência e a arte de criar instruções para espaços organizados". O autor encarava o problema de busca, organização e apresentação da informação como análogo aos problemas da arquitetura de construções que irão servir às necessidades de seus moradores (MACEDO, 2005).

$\mathrm{Na}$ literatura, podem ser encontradas várias definições para o termo Arquitetura da Informação, muitas delas fortemente influenciadas pela rápida evolução da internet. A seguir, são apresentadas algumas das definições mais relevantes para o estudo em questão.

Para Bailey (2003, p.9), Arquitetura da Informação "é arte e a ciência de estruturar e organizar sistemas de informação com o intuito de ajudar as pessoas a atingirem o seu objetivo". Arquitetos de informação organizam conteúdos e projetam sistemas de navegação para auxiliar as pessoas a encontrar e gerenciar informação.

Brancheau e Wetherbe (1986 apud VICTORINO, 2011) afirmam que Arquitetura da Informação consiste em um plano para modelagem dos requisitos informacionais de uma organização, que provê um modo de mapear as informações necessárias à própria organização, relativas aos processos do negócio e à documentação de seus inter-relacionamentos.

Davenport (1998), em seu modelo ecológico de gestão da informação, define Arquitetura da Informação como "um guia para estruturar e localizar a informação dentro de uma organização". Em um sentido mais amplo, o autor afirma que a arquitetura da informação simplesmente se constitui em uma série de ferramentas que adaptam os seus recursos às necessidades da informação, estruturando dados em formatos, categorias e relações específicas e fazendo a ligação entre o comportamento organizacional, os processos, as pessoas e outros aspectos da organização.

McGee e Prusak (1994) ressaltam que a arquitetura da informação define qual a informação mais importante para a organização.

Para Rosenfeld e Morville (2006), a arquitetura da informação pode ser 
representada pela intersecção entre usuários, conteúdos e contexto que se relacionam de forma interdependente. Uma boa arquitetura da informação, na opinião dos autores, envolve a integração desses três elementos.

Influenciada por Rosenfeld e Morville, Macedo (2005) define Arquitetura da Informação, sob uma perspectiva sistêmica, como:

uma metodologia de desenho que se aplica a qualquer ambiente informacional, sendo este compreendido como um espaço localizado em um contexto; constituído por conteúdos em fluxo; que serve a uma comunidade de usuários. A finalidade da arquitetura da informação é, portanto, viabilizar o fluxo efetivo de informações por meio do desenho de ambientes informacionais. (MACEDO, 2005).

Percebe-se, portanto, que o foco da arquitetura da informação está na organização da informação de forma a atender as necessidades e comportamentos de busca dos usuários, considerado o contexto do ambiente informacional. A criação de uma arquitetura da informação bem definida, estabelecida de comum acordo e gerenciada de forma coerente, permite que todas as partes envolvidas numa empresa falem a mesma língua e utilizem a informação para a tomada de decisões significativas (MCGEE e PRUSAK, 1994).

\subsection{Arquitetura e Gestão da Informação}

Segundo McGee e Prusak (1994, p.13), processo e arquitetura devem ser dimensões do gerenciamento de informações que se reforçam mutuamente. $O$ processo focaliza os aspectos dinâmicos do gerenciamento de informação, enquanto a arquitetura da informação focaliza a definição e o estabelecimento efetivo do espaço da informação dentro do qual o processo de gerenciamento ocorre.

Para os autores (1994, p.108), o processo de gestão de informação corresponde ao conjunto ordenado das seguintes tarefas: identificação de necessidades e requisitos de informação; classificação e armazenamento de informação; tratamento e apresentação de informação; desenvolvimento de produtos e serviços de informação; distribuição e disseminação de informação.

De forma semelhante, Choo (2003, p.394) sugere que a gestão da informação seja vista como a administração de uma rede de processos que adquirem, criam, organizam, distribuem e usam a informação. O resultado do uso eficiente da informação é o comportamento adaptativo, ou seja, a seleção e execução de ações 
dirigidas para os objetivos, mas que também reagem às condições do ambiente.

De acordo com Davenport (1998), a gestão da informação corresponde a um conjunto estruturado de atividades que incluem o modo como as empresas obtêm, distribuem e usam a informação e o conhecimento. $O$ autor propõe um modelo ecológico para gestão da informação onde o ambiente informacional, núcleo da abordagem ecológica, está contido no ambiente organizacional e ambos são afetados pelo ambiente externo. O ambiente informacional é composto por: estratégia da informação, política da informação, cultura e comportamento em relação à informação, equipe da informação, processos de gestão informacional e arquitetura da informação que, segundo a abordagem proposta pelo autor, consiste em um guia para estruturar e localizar a informação dentro de uma organização.

O modelo apresentado a seguir por Macedo (2005) baseia-se nas definições de arquitetura da informação e nos processos de gestão da informação para sugerir a implantação de uma arquitetura da informação na prática. De forma semelhante, Victorino e Bräscher (2009) propuseram um processo de modelagem da informação para viabilizar a implantação de uma arquitetura da informação, cujos alicerces apresentados por Victorino (2011) fundamentaram as diretrizes propostas neste trabalho.

\subsection{Aspectos práticos da Arquitetura da Informação}

Macedo (2005) sugere um modelo genérico para a implantação de uma arquitetura da informação, o qual é apresentado na figura 1.

Figura 1 - Modelo genérico de arquitetura da informação

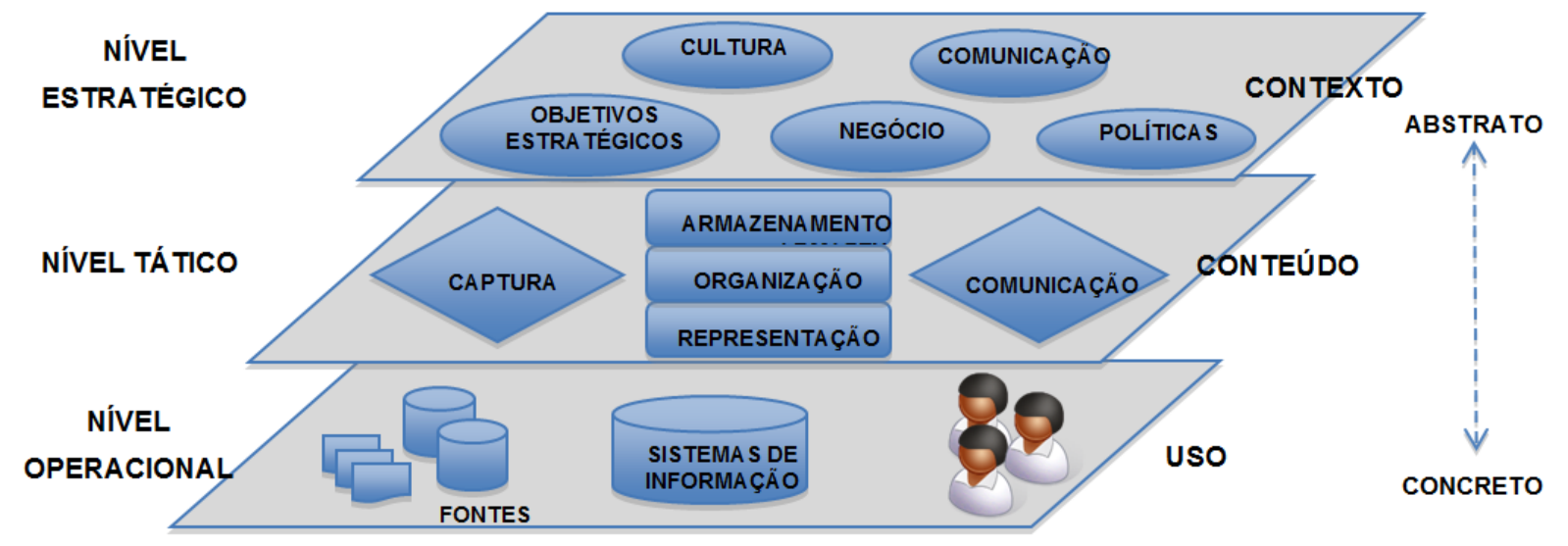

Fonte: Adaptado de Lima-Marques e Macedo, 2005, p. 165 
No modelo acima, o primeiro nível é considerado como estratégico, sendo essencialmente o nível de análise do ambiente informacional a ser desenhado. Este nível fornece, portanto, o arcabouço teórico que irá servir de base para a modelagem do ambiente informacional. O nível tático é aquele onde são definidos os modelos relacionados ao contexto. Neste nível, é realizada a modelagem dos processos de captura, tratamento e comunicação da informação. O nível operacional é aquele no qual se aplicam as teorias, modelos técnicas e tecnologias idealizadas nos níveis anteriores para a implementação do sistema de informação, com seus produtos e serviços. Este é o nível que viabiliza o uso do ambiente informacional.

A literatura, em um sentido mais amplo, considera sistemas de informação como sinônimo de ambientes de informação, referindo-se a serviços de informação propriamente ditos, tais como bibliotecas ou centros de informação. Em um sentido mais restrito, referem-se aos sistemas de recuperação de informação, tais como catálogos de bibliotecas, bases de dados e sistemas automatizados em geral (MACEDO, 2005).

Victorino e Bräscher (2009), utilizando uma abordagem holística, propõem um processo de modelagem da informação, visando à materialização de uma arquitetura da informação. Os alicerces desse processo são representados por Victorino (2011) na figura 2. Apesar de o autor não considerar explicitamente a construção de glossários de negócios como artefatos da modelagem da informação, entende-se que a elaboração de um glossário com definições consensuais e comuns à organização é um passo fundamental para a integração de suas informações, um dos objetivos da arquitetura da organização. De acordo com Lara e Tálamo (2007), os glossários, assim como os dicionários terminológicos e vocabulários, constituem um produto terminológico. Funcionalmente, a Terminologia é veículo de conhecimento, aspecto importante para a descrição e recuperação da informação.

Por este motivo, a figura 2 foi adaptada pela autora deste artigo para a inclusão de metodologias para construção de glossários de negócio como um dos alicerces da modelagem da informação. 
Figura 2 - Alicerces do processo de modelagem da informação

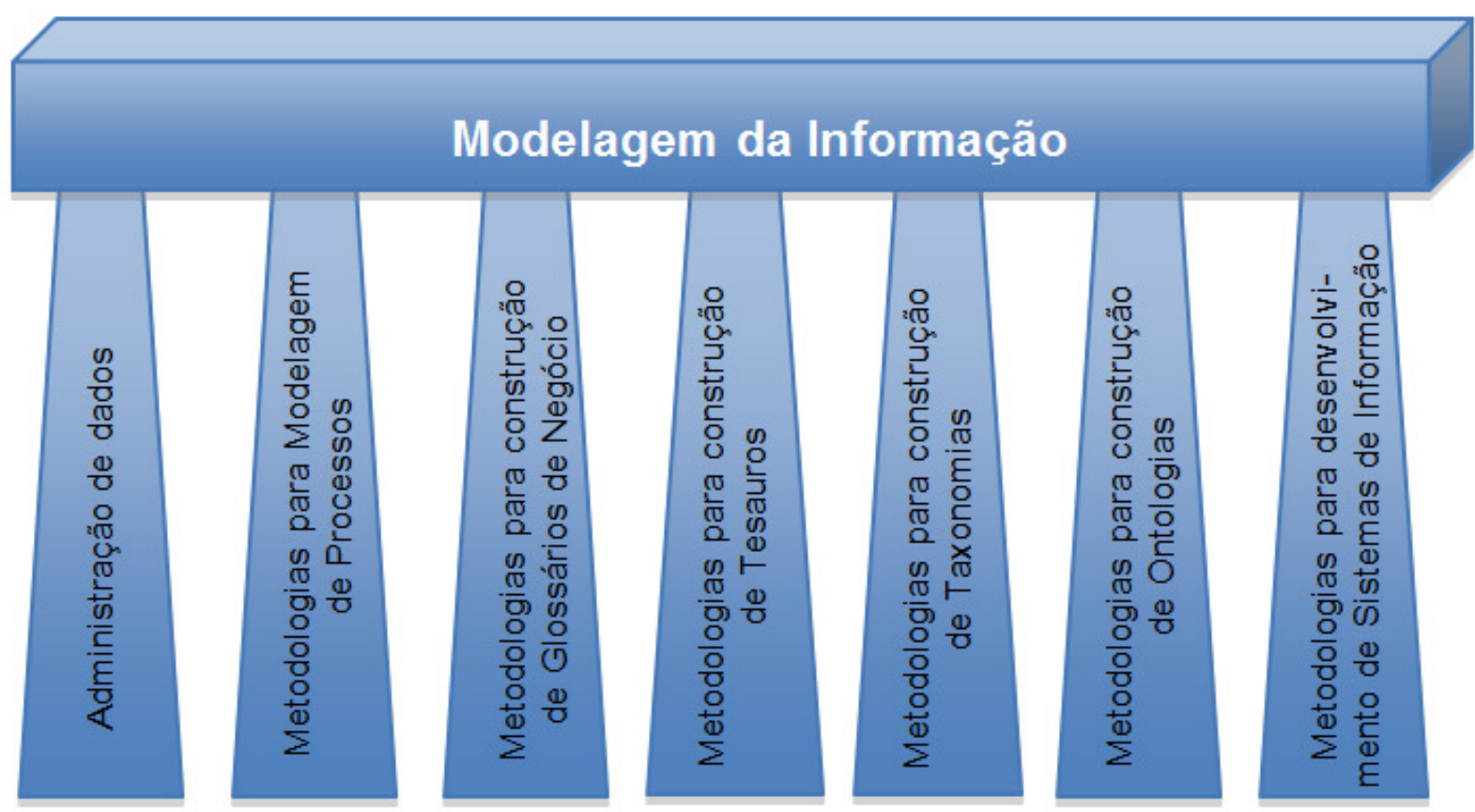

Fonte: Adaptado de Victorino, 2011, p. 99.

De acordo com Victorino e Bräscher (2009), os principais artefatos gerados a partir desta modelagem são, entre outros, metadados relacionados aos objetos informacionais e os sistemas de organização do conhecimento (SOC): taxonomias, tesauros e ontologias. $\mathrm{O}$ objetivo de gerar estes artefatos é representar física e semanticamente os objetos informacionais que os sistemas organizacionais manipulam e o domínio em que estão inseridos.

Para Bräscher e Café (2008, p. 8), os sistemas de organização do conhecimento "são sistemas conceituais que representam determinado domínio por meio da sistematização dos conceitos e das relações semânticas que se estabelecem entre eles". Tais sistemas possibilitam a representação do conhecimento e cumprem a função de padronizar a representação da informação no que se refere à identificação dos assuntos do documento.

$\mathrm{Na}$ abordagem proposta por Victorino e Bräscher (2009), reforçada posteriormente por Victorino (2011), a modelagem de processos fornece a documentação dos processos e das informações por eles geradas e utilizadas. A modelagem da informação gera os metadados dos objetos informacionais manipulados pelos processos e os tesauros, taxonomias e ontologias que representam o domínio observado. A modelagem de software gera os dados e os requisitos dos sistemas de informação. 
Os autores ressaltam ainda que os produtos de trabalho mais importantes resultantes do processo de modelagem da informação são o repositório informacional corporativo e os sistemas de organização do conhecimento, conectados harmoniosamente por meio de uma arquitetura da informação.

\section{METODOLOGIA}

A presente pesquisa caracteriza-se como sendo qualitativa, metodológica e aplicada. A pesquisa qualitativa é indutiva, isto é, o pesquisador desenvolve conceitos, ideias e entendimentos a partir de padrões encontrados nos dados, ao invés de coletar dados para comprovar teorias, hipóteses e modelos preconcebidos (RENEKER,1993 apud MORESI, 2003).

A abordagem qualitativa foi utilizada porque o estabelecimento de diretrizes para uma metodologia de modelagem da informação para a Câmara dos Deputados, além de não ser propriamente quantificável, envolve o levantamento e a descrição das características do ambiente informacional da instituição.

De acordo com Godoy (1995), a abordagem qualitativa oferece três diferentes possibilidades de se realizar a pesquisa: a pesquisa documental, o estudo de caso e a etnografia.

Para a realização deste trabalho, foi utilizada a pesquisa documental que, segundo Neves (1996, p.3), "é constituída pelo exame de materiais que ainda não receberam um tratamento analítico ou que podem ser reexaminados com vistas a uma interpretação nova ou complementar". Como fonte de consulta, foram utilizados normas, relatórios, sistemas e documentos publicados no Portal da Câmara dos Deputados que abordam as práticas informacionais na Casa. Em especial, foi examinada a documentação do PGIC e do projeto de Arquitetura de Informação. O intuito foi descrever o ambiente informacional da $C D$, tomando como base 0 levantamento dos aspectos relativos aos componentes do ambiente informacional elencados no modelo ecológico de gestão da informação proposto por Davenport (1998): estratégia, equipe, política, cultura/comportamento, processo e arquitetura.

Pelo fato de estabelecer diretrizes para uma metodologia de modelagem da informação, essa pesquisa tem caráter metodológico. Segundo Moresi (2003), a pesquisa metodológica é o estudo que se refere à elaboração de instrumentos de captação ou de manipulação da realidade. Está, portanto, associada a caminhos, 
formas, maneiras e procedimentos para atingir determinado fim.

Quanto a seus objetivos, pode ser considerada uma pesquisa aplicada, pois visa gerar conhecimentos, para aplicação prática, dirigidos à solução de problemas específicos (MORESI, 2003). De fato, este trabalho pretende fornecer o embasamento necessário para a elaboração do segundo produto do projeto de Arquitetura de Informação, que é a metodologia de implantação de um modelo de Al na Câmara dos Deputados.

Inicialmente, foi realizada a descrição do ambiente informacional da CD, com base no levantamento e na análise dos documentos que abordam as práticas informacionais e de desenvolvimento de sistemas de informação, bem como o histórico dos processos de informatização na Casa. Também, foi examinada a documentação referente ao planejamento estratégico, ao Programa de Gestão da Informação e do Conhecimento e ao Projeto de Arquitetura de Informação. Subsidiariamente, foram consultadas as áreas de informação e de informática para esclarecimentos complementares.

Após as etapas de levantamento e análise documental, passou-se à análise, do ponto de vista teórico, dos elementos que compõem uma arquitetura da informação e da forma como implantá-los em uma organização, em confronto com as práticas informacionais da $\mathrm{CD}$. Como resultado, tendo como foco os objetivos pretendidos pelo projeto de Arquitetura de Informação, chegou-se aos subsídios para a elaboração das diretrizes para uma metodologia de modelagem da informação aplicada às necessidades da instituição.

\section{PROPOSTA DE MODELAGEM DA INFORMAÇÃO PARA O AMBIENTE INFORMACIONAL DA CÂMARA DOS DEPUTADOS}

\subsection{Ambiente informacional da Câmara dos Deputados}

A Câmara dos Deputados trabalha com um volume grande de informações, estruturadas e não estruturadas, provenientes de fontes internas e externas, acumuladas ao longo de 190 anos de existência. Apenas na área legislativa, tramitam anualmente mais de 20.000 documentos, entre propostas de lei e 
documentos diversos relativos ao processo legislativo ${ }^{3}$. Além do volume, a principal informação produzida pela CD no exercício de suas atribuições legislativas, de fiscalização e controle e representativas estabelecidas pela Constituição Federal de 1988, no Título IV - Organização dos Poderes, Capítulo I - Do Poder Legislativo, é, nos termos dos artigos 48 a 51, multidisciplinar, já que trata sobre os mais variados temas (saúde, tecnologia, transporte, segurança, etc.). Essa diversidade de assuntos é retratada por alguns órgãos da $C D$, tais como a Consultoria Legislativa e as Comissões Permanentes, cuja estrutura compreende várias áreas do conhecimento, refletindo a realidade das matérias afeitas à apreciação legislativa.

Ao longo dos últimos quinze anos, as orientações relativas à informação na Câmara dos Deputados foram difusas e muitas vezes não alinhadas a um objetivo corporativo comum. Esse fato pode ser ilustrado pela quantidade de comitês e grupos de trabalho criados para tratar questões relativas à informação e sua informatização, tanto na área legislativa quanto na administrativa, cujos resultados, de acordo com Alarcão (2011), na sua maioria, não são conhecidos ou percebidos na prática porque nem sempre redundam em melhorias significativas para a gestão da informação corporativa. A partir de 2004, começaram a ser adotadas ações para pôr em execução o Planejamento Estratégico na Casa. Essas ações resultaram no mapa estratégico corporativo da CD e deram origem a doze programas/projetos, dentre os quais se destaca o Programa de Gestão da Informação e do Conhecimento, que contempla a elaboração de políticas informacionais corporativas, de um modelo de $\mathrm{Al}$, do tesauro da $\mathrm{CD}$ e de requisitos de gestão de conteúdos ${ }^{4}$.

O modelo de Al faz parte do escopo do projeto de Arquitetura da Informação que prevê ainda, entre as suas entregas, a elaboração de uma metodologia, cujas diretrizes são o objeto de estudo desta pesquisa. O termo 'diretriz', de acordo com o dicionário Houaiss significa "esboço, em linhas gerais, de um plano, projeto, etc.; diretiva" (2001). No mesmo dicionário, o termo 'diretiva' é definido como: "instrução ou conjunto de instruções para a execução de um plano, uma ação, um empreendimento, etc." (2001). Dessa forma, as diretrizes propostas a seguir representam um conjunto de instruções que esboçam, em linhas gerais, uma metodologia para implantação de uma arquitetura da informação, neste trabalho

\footnotetext{
${ }^{3}$ FONTE: SILEG - Sistema de Informações Legislativas da Câmara dos Deputados. Acesso em: 10 de dezembro de 2012.

${ }^{4}$ FONTE: Intranet da Câmara dos Deputados, disponível em: <https://camaranet.camara.gov.br/web/ gestaoestrategicagestao-estategica>. Acesso em 09 de fevereiro de 2013.
} 
denominada de modelagem da informação.

Essa metodologia deverá, de acordo com os objetivos do projeto de Al, abordar princípios de organização da informação e do conhecimento, além abarcar as etapas do processo de gestão da informação. O objetivo é organizar e integrar as informações da CD, permitindo a implantação de um modelo de Al que viabilize a gestão da informação institucional.

\subsection{Diretrizes para modelagem da informação}

Com base nos alicerces do processo de modelagem da informação propostos por Victorino (2011) e nos modelos de gestão da informação apresentados por Choo (2003) e por McGee e Prusak (1994), foram propostas as diretrizes abaixo.

\subsubsection{Para a modelagem da informação, deve ser realizada a modelagem dos processos de negócio}

Na modelagem de processos, as necessidades dos usuários são levantadas e o contexto organizacional é descrito, permitindo a modelagem do espaço informacional (VICTORINO, 2011). Adicionalmente, a modelagem de processos de negócio viabiliza a eliminação das redundâncias no registro da informação, ao longo dos processos de trabalho, possibilitando a integração de fluxos e de repositórios de informação, objetivos almejados pelo Projeto de Arquitetura da Informação.

Apesar de possuir seus principais processos de trabalho identificados pelo Plano de Classificação Funcional, taxonomia desenvolvida para classificação documental pelo grupo de trabalho instituído pela Portaria $n^{\circ}$ 86, de 23 de julho de $2003^{5}$, as iniciativas de mapeamento e modelagem de processos na CD ainda ocorrem de forma isolada, em áreas específicas. Portanto, a implantação de uma arquitetura da informação na Casa terá como desafio o mapeamento e a modelagem de processos, ação que dependerá de uma articulação da gestão estratégica com as áreas de negócio.

Diante de tal cenário, a sugestão é que a modelagem da informação seja realizada em conjunto com a modelagem de processos. Além de representar uma economia de esforços, enquanto a modelagem de processos fornece a

\footnotetext{
${ }^{5}$ Disponível em: <http://www2.camara.leg.br/legin/int/portar/2003/portaria-86-23-julho-2003-321989norma-cd-dg.html . Acesso em 20 de fevereiro de 2013.
} 
documentação dos processos, a modelagem da informação se preocupa em documentar os objetos informacionais gerados pelos processos, descrevendo conceitos, características de suporte, conteúdo, preservação, etc. e a relação do objeto informacional com o domínio de informação no qual se encontra inserido.

\subsubsection{0 processo de modelagem da informação deve ser pré-requisito para o desenvolvimento de sistemas de informação}

Uma vez que o processo de modelagem da informação fornece a documentação dos objetos informacionais e de seus metadados para a construção dos sistemas, deve ser pré-requisito para o desenvolvimento de sistemas de informação. Preferencialmente, esses processos devem ocorrer de maneira integrada, possibilitando que glossários, tesauros e ontologias sejam consultados no momento da concepção dos sistemas, evitando a criação de informações redundantes e de modelos de dados e regras de negócio que não refletem a semântica real dos processos de trabalho que serão informatizados.

De acordo com Victorino (2011), é a modelagem da informação que detalha o suporte, o conteúdo e o relacionamento desses objetos informacionais com 0 domínio no qual se encontram inseridos, informações essenciais para o desenvolvimento dos sistemas de informação.

$\mathrm{Na}$ diretriz proposta, o desenvolvimento de sistemas de informação não pode ser realizado sem a prévia modelagem da informação e sem a consulta aos sistemas de organização do conhecimento em construção na CD.

\subsubsection{A equipe que realiza a modelagem da informação deve ser multidisciplinar e deve trabalhar em conjunto com analistas de processos de negócio e com analistas de sistemas}

Para Davenport (1998, p.53), uma boa equipe informacional "inclui diferentes tipos de pessoas, como especialistas em conteúdo (bibliotecários e pesquisadores de mercado), projetistas, facilitadores de bases informacionais e elos de ligação (guias que ajudam os usuários a identificar suas necessidades)". Segundo o autor, essas pessoas devem ser capazes de agregar valor à informação e interpretar o conteúdo dos dados.

No caso da $C D$, além de profissionais especializados em informação, considerando o tamanho da instituição, é importante que a equipe esteja 
familiarizada com as políticas informacionais, conheça os objetivos e projetos estratégicos, as fontes de informação utilizadas e tenha facilidade de acesso à tecnologia da informação.

É importante também que a equipe de informação trabalhe com analistas de processos negócio, durante a modelagem de processos, e com analistas de sistemas, durante a concepção dos sistemas de informação. McGee e Prusak (1994, p. 116) destacam a importância do trabalho conjunto entre especialistas em informação e analistas de sistemas ao afirmarem que, quando esses profissionais trabalham juntos, podem produzir um conjunto de requisitos de informação muito mais rico e estratégico que qualquer outro produzido por um só grupo trabalhando em separado.

\subsubsection{Para a modelagem da informação é necessário identificar os requisitos de informação}

O levantamento dos requisitos informacionais envolve a identificação das necessidades de informação do usuário, que é a primeira etapa dos modelos de gestão da informação propostos por Choo (2003) e por McGee e Prusak (1994). Segundo Choo (2003, p.396), é nesta atividade que são levantados os padrões e o significado da informação, condições e regras de uso que tornam a informação significativa para um conjunto de indivíduos. Para Victorino (2011), sua finalidade é oferecer às pessoas que interagem com o domínio observado uma compreensão dos conceitos relevantes, estabelecer padrões de metadados e demarcar as fronteiras do domínio. É nesta etapa, portanto, que devem ser levantados os termos, seus conceitos e relacionamentos para a construção de glossários de negócio, tesauros e ontologias, além de serem estabelecidos os metadados que irão compor o repositório de metadados.

\subsubsection{Construção de glossário de negócios}

Um glossário corporativo de negócios é fundamental para unificação terminológica, pois diminui a ambiguidade da informação e aumenta confiança dos tomadores de decisão ao interpretar e utilizar os dados dos sistemas de informação, especialmente dos sistemas de Data Warehouse. Além disso, possui papel importantíssimo de integração, viabilizando os processos de compartilhamento da 
informação. Portanto, representa um elemento essencial para a implantação da arquitetura da informação.

Para McGee e Prusak (1994, p.165), um vocabulário comum quer dizer "um conjunto acordado de termos, categorias e elementos de dados que tenham o mesmo significado em toda a organização". É um componente tão importante para a gestão da informação que os autores destacaram-no como uma das quatro dimensões de avaliação dos modelos de gestão da informação, juntamente com o grau de acesso à informação significativa, a qualidade da informação e a eficiência no gerenciamento da informação.

$\mathrm{Na}$ diretriz proposta, a recomendação é que o glossário seja unificado e construído por profissionais de informação, em conjunto com as áreas de negócio, usando metodologias para construção de glossários de negócio.

\subsubsection{Construção de tesauros e ontologias}

O relacionamento entre os termos levantados e conceituados na etapa de identificação das necessidades de informação permite o desenvolvimento de tesauros e ontologias.

O Tesauro da Câmara dos Deputados (Tecad) é um dos projetos previstos pelo PGIC. Ainda não foi concluído, mas a base de termos existentes é utilizada, de forma não integrada, para a indexação de bases de informação da Câmara, tais como proposição e legislação. A integração do Tecad aos sistemas de informação da $C D$ e às ferramentas de busca corporativa é um dos requisitos estabelecidos pelas políticas de informação do PGIC.

$\mathrm{Na}$ diretriz proposta, os termos levantados durante a identificação das necessidades de informação das áreas de negócio devem ser relacionados pela equipe do tesauro, passando a integrar o Tecad. A grande vantagem desse procedimento feito durante o processo de modelagem da informação é que os termos não precisam de validação posterior, uma vez que são fornecidos pelas próprias áreas de negócio. Dessa forma, assegura-se a "garantia de usuário", uma das bases para a construção de tesauros.

O relacionamento de termos também poderia ser utilizado para a construção de ontologias. A Câmara dos Deputados não possui projetos voltados para o 
assunto. No entanto, a implantação da arquitetura da informação por meio de uma metodologia de modelagem da informação pode vir a fomentar este tipo de iniciativa.

\subsubsection{Definição de metadados}

Os metadados são elementos de organização da informação que possibilitam a descrição dos objetos informacionais sob diferentes perspectivas: conteúdo, gestão, preservação, etc. Segundo Victorino (2011), os tipos de metadados armazenados dependem da organização-alvo. Sugere, no entanto, que sejam estabelecidos, no mínimo, os metadados estruturais (que descrevem o suporte físico de um objeto informacional) e os metadados descritivos (que descrevem as características intelectuais do conteúdo de um objeto informacional).

Os metadados para descrição dos objetos informacionais da Câmara dos Deputados estão especificados, de uma forma geral, nos objetivos e requisitos das políticas de informação oriundas do PGIC. A análise dessas políticas aponta para o estabelecimento de metadados administrativos, estruturais e descritivos.

\subsubsection{Após a identificação dos requisitos informacionais, deverão ser planejadas as tarefas de organização e armazenamento da informação}

A organização da informação envolve a sua classificação. Segundo McGee e Prusak (1994, p. 118), a classificação e o armazenamento da informação pressupõem a determinação de como os usuários poderão ter acesso às informações necessárias e selecionar o melhor lugar para armazená-las. Os mesmos autores ainda recomendam que os esquemas de classificação utilizados sejam tão variados quanto a natureza do material representado.

$\mathrm{Na}$ diretriz proposta, a sugestão é que as informações sejam classificadas e armazenadas conforme os requisitos estabelecidos pela Política de Gestão de Conteúdos Informacionais, que determina a utilização de instrumentos de classificação e taxonomias corporativos, além de repositórios corporativos que assegurem a identidade única de cada objeto informacional.

Victorino e Bräscher (2009) sugerem a criação de um repositório informacional corporativo composto por: objetos informacionais gerados internamente; objetos informacionais gerados externamente, porém copiados para o repositório; referências a objetos informacionais externos; e metadados. O 
repositório informacional corporativo conectado aos sistemas de organização do conhecimento possibilita a implantação de um modelo genérico de arquitetura da informação proposto pelos autores na figura 4.

Figura 4 - Visão lógica da Arquitetura da Informação - Modelo genérico

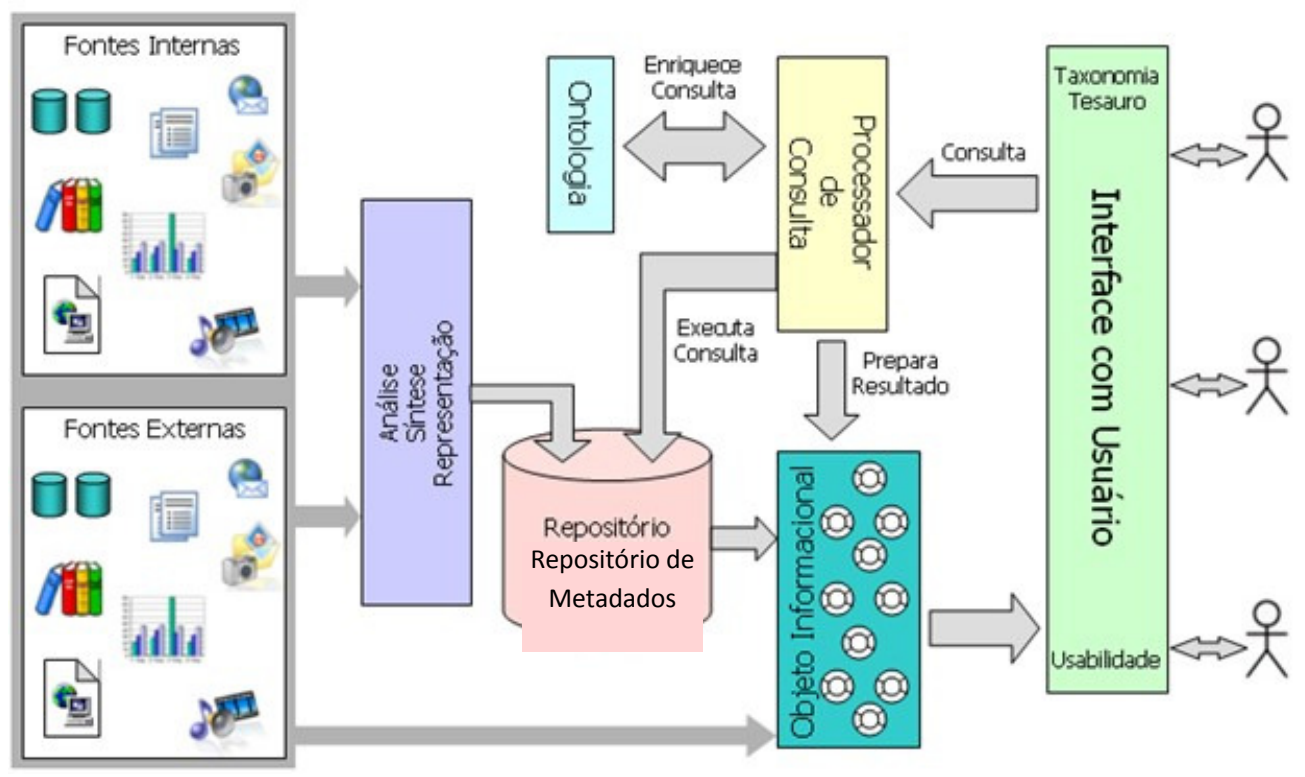

Fonte: Victorino; Bräscher, 2009

No modelo acima, o usuário interage com uma interface para a busca de informação. Os tesauros são utilizados para permitir ao usuário encontrar o termo que represente um determinado significado para o que procura. Já as taxonomias navegacionais são utilizadas para permitir que os usuários leigos naveguem pelo conteúdo do repositório e, por esse motivo, são criadas levando em conta o comportamento do usuário. As taxonomias descritivas auxiliam os especialistas em suas buscas por informações. Finalmente, as ontologias permitem o aprimoramento das buscas realizadas pelos usuários com a delimitação do contexto (VICTORINO e BRÄSCHER, 2009).

O modelo genérico de Al proposto, apesar de contemplar a construção de uma ontologia, ainda não prevista formalmente nos projetos da Casa, está de acordo com os objetivos e requisitos das políticas de informação da Câmara dos Deputados e com os objetivos do projeto de Arquitetura da Informação de organizar e integrar as informações. 


\subsection{A modelagem da informação e os processos de gestão da informação}

A gestão efetiva da informação nas organizações se inicia com os processos de Identificação das Necessidades de Informação e Aquisição da Informação (CHOO, 2003). Esses processos são viabilizados pelo entendimento do contexto informacional e pelo mapeamento dos processos organizacionais. As diretrizes 4.2.1 e 4.2.4 apoiam esses processos, propiciando a compreensão dos conceitos relevantes e dos seus relacionamentos dentro do domínio analisado, além de permitir o estabelecimento de metadados dos processos modelados e dos objetos informacionais.

O processo de Organização e Armazenamento da Informação, que no modelo proposto por Choo (2003) subsidia quase todos os demais processos de gestão da informação, é viabilizado pela diretriz 4.2.5 e materializado por meio do repositório informacional corporativo. Esse repositório é povoado com objetos informacionais, metadados, informações sobre o domínio no qual a organização está inserida e seus inter-relacionamentos.

As diretrizes 4.2.2, 4.2.4 e 4.2.5 apoiam os demais processos de gestão da informação: Desenvolvimento de Produtos e Serviços de Informação, Distribuição e Uso da Informação, os quais possibilitam o uso do ambiente informacional e a implantação da arquitetura da informação na prática. Um modelo de Al implantado, contendo todos os elementos expostos neste artigo, permite a utilização eficaz da informação pelas organizações que, de acordo com Choo (2003, p.395), resulta em um comportamento adaptativo, gerando a busca por novas informações e mantendo o ciclo de uso da informação.

As diretrizes também vão ao encontro dos atributos-chave do modelo ecológico de gestão da informação proposto por Davenport (1998): integração dos diversos tipos de informação, reconhecimento de mudanças evolutivas, ênfase na observação e na descrição e ênfase no comportamento pessoal e informacional.

Dessa forma, pode-se concluir que as diretrizes aqui propostas contribuem para a adoção de mecanismos de governança eficazes para a gestão da informação institucional, um dos objetivos almejados pelo projeto de Arquitetura de Informação da CD. 


\section{CONSIDERAÇÕES FINAIS}

Esta pesquisa originou-se da necessidade do projeto de Arquitetura de Informação da Câmara dos Deputados de estabelecer uma metodologia para a implantação de um modelo de Al na instituição. Teve como propósito desenvolver diretrizes para a elaboração dessa metodologia, denominada modelagem da informação.

Tendo em vista os objetivos estabelecidos pelo projeto de compartilhamento e de integração das informações corporativas, de forma a possibilitar a adoção de mecanismos para a gestão da informação institucional, a revisão da literatura identificou os conceitos teóricos e os elementos constituintes de uma arquitetura da informação importantes para a compreensão de como os recursos de organização da informação e do conhecimento podem ser conectados na prática para implantar um modelo de Al. Também foram apresentados os princípios de gestão da informação, necessários para subsidiar a elaboração das diretrizes propostas.

Constatou-se que, para organizar a informação, é necessário realizar a sua descrição física e de conteúdo e que o resultado dessa descrição é a representação da informação, que consiste no objeto da modelagem da informação. Verificou-se também que os produtos mais importantes do processo de modelagem da informação são o repositório informacional corporativo e os sistemas de organização do conhecimento, conectados por meio de uma arquitetura da informação.

A descrição do ambiente informacional da CD possibilitou o entendimento do contexto organizacional no qual o projeto de Al encontra-se inserido, fornecendo uma visão do principal problema que a implantação de um modelo de Al pretende abordar, que é a falta de organização e de integração das informações corporativas.

Por fim, foram estabelecidas as diretrizes para a modelagem da informação, buscando agregar os elementos teóricos de organização da informação, organização do conhecimento e gestão da informação às iniciativas em andamento na Câmara dos Deputados e às orientações das políticas de informação oriundas do Programa de Gestão da Informação e do Conhecimento, especialmente a Política de Gestão de Conteúdos Informacionais. Apesar de o projeto de Al abarcar a organização de informações de quaisquer tipos e em quaisquer formatos, as diretrizes propostas neste artigo enfatizaram a organização de informações em 
sistemas computadorizados, as quais representam a principal fonte de inconsistência apontada pelo projeto.

Por estarem baseadas nos processos de gestão da informação propostos por Choo (2003) e por possibilitarem a implantação do modelo genérico de arquitetura da informação sugerido por Victorino e Bräscher (2009), observa-se que as diretrizes para modelagem da informação podem ser aplicadas não somente à $C D$, mas também a outras organizações que desejam implantar uma arquitetura da informação com os elementos de organização da informação apresentados neste artigo.

No âmbito da Câmara dos Deputados, a aplicação das diretrizes demandará a definição de novas atribuições, alterações em processos e equipes de trabalho, além de mudanças na forma como a instituição lida com a informação.

Um dos primeiros esforços a ser empreendido é o detalhamento dos metadados, de acordo o exposto na Seção 4.2.4.3, e a construção da metodologia de modelagem da informação propriamente dita (definição de procedimentos, técnicas, formulários e outros artefatos), com base nas diretrizes apresentadas.

Do ponto de vista dos processos de trabalho, uma das principais alterações deverá ocorrer no processo de desenvolvimento de sistemas de informação, que, dentro da nova proposta, precisará ser necessariamente precedido da modelagem dos processos de negócio e da modelagem da informação. A recomendação é que esses processos sejam conduzidos, preferencialmente, de forma integrada. Quanto às equipes de trabalho, observa-se a necessidade de alteração em sua composição para agregar profissionais de informação.

O maior desafio para a implantação das diretrizes para modelagem da informação, no entanto, está na mudança da cultura e comportamento com relação à informação. Estimular comportamentos favoráveis à implantação de uma arquitetura informacional na Câmara dos Deputados, tais como o compartilhamento de informações, não é uma tarefa simples, pois envolve alterações no modo como as pessoas lidam com a informação. A Câmara tem apresentado alguns avanços nessa área, por meio da execução de projetos estratégicos. Todavia, os avanços ainda são lentos, tendo em vista os esforços realizados neste sentido por grupos de trabalhos anteriores.

Um importante fato constatado a partir da análise das políticas de informação é que a base legal para a implantação de uma arquitetura da informação na Câmara 
dos Deputados encontra-se estabelecida. É preciso tornar efetiva a aplicação dessas políticas e as diretrizes propostas neste trabalho representam um meio para atingir esse objetivo.

Os esforços para a implantação do modelo de Al devem possibilitar que a modelagem de processos, a modelagem da informação e o desenvolvimento de sistemas de informação alcancem de forma efetiva os processos de captura, tratamento e comunicação da informação. $O$ trabalho deve tentar conciliar inclusive as informações atualmente registradas nos sistemas locais e nos servidores de arquivos compartilhados por órgão, permitindo que os sistemas de informação reflitam a prática informacional das unidades administrativas e possibilitem a diminuição ou eliminação de redundâncias e de inconsistência de informações.

Espera-se que uma arquitetura da informação implantada utilizando uma metodologia de modelagem da informação elaborada com base nas diretrizes propostas neste artigo organize de forma efetiva as informações de interesse corporativo da Câmara dos Deputados, garantindo o seu uso de forma tempestiva e confiável, seja para a execução de suas atividades, seja para a tomada de decisão, seja para atender à sociedade.

Durante a realização desta pesquisa, não foi possível tratar com profundidade alguns dos temas abordados, tais como os metadados dos objetos informacionais. Dessa forma, em continuidade, sugerem-se os seguintes trabalhos futuros: especificação detalhada dos metadados dos objetos informacionais com base nas políticas do PGIC; elaboração dos artefatos da metodologia de modelagem da informação e criação de ontologias para a Câmara dos Deputados.

\section{REFERÊNCIAS}

ALARCÃO, C. M. A. A Gestão da Informação Legislativa na Câmara dos

Deputados. 2011. Disponível em: <http://bd.camara.gov.br/bd/handle/bdcamara/ 10231 >. Acesso em: 12 de janeiro de 2013.

BAILEY, S. Information architecture: a brief introduction. 2003. Disponível em: $<$ http://aifia.org/tools/download/Bailey-IAlntro.pdf>. Acesso em 23 jan. 2013. 
BRÄSCHER, M.; CAFÉ, L. Organização da Informação ou Organização do Conhecimento? In: ENCONTRO NACIONAL DE PESQUISA EM CIÊNCIA DA INFORMAÇÃO, 9, 2008, São Paulo, Anais. São Paulo: ANCIB, 2008. Disponível em: <www.ancib.org.br/media/dissertacao/1835.pdf>. Acesso em: 10 nov. 2012.

BRASIL. Constituição (1988). Constituição da República Federativa do Brasil. 26 ed. Brasília: Câmara dos Deputados, Coordenação de Publicações, 2008.

BRASIL. Câmara dos Deputados. Programa de Informatização da Atividade Legislativa. Relatório de Atividades. Uma abordagem sobre a gestão da informação para o desenvolvimento do N-Sileg. Documento encaminhado à Coordenação de Arquivo da Câmara dos Deputados em 26/03/2009. Processo no 110019/2009. Não publicado.

. Portal da Câmara dos Deputados. Disponível em: <http://www2.camara.leg.br>. Acesso em 25 jan. 2013.

CHOO, C. W. A Organização do Conhecimento. 3. ed. São Paulo: Senac, 2011. DAVENPORT, T. H. Ecologia da informação. 6. ed. São Paulo: Futura, 1998.

GODOY, A. S. Introdução à pesquisa qualitativa e suas possibilidades. RAE Revista de Administração de Empresas. São Paulo, v.35, n. 2, p. 57-63, 1995. Disponível em: <http://rae.fgv.br >. Acesso em 02 dez. 2012.

HOUAISS, A. Dicionário Eletrônico Houaiss da Língua Portuguesa. Instituto Antônio Houaiss, editora Objetiva LTDA, 2001.

LARA, M. L. G.; TÁLAMO, M. F. G. M. Uma experiência na interface Linguística Documentária e Terminologia. DataGramaZero - Revista de Ciência da Informação - v.8 n.5, out/07. Disponível em: <http://www.dgz.org.br/out07/art_01.htm>. Acesso em 12 dez. 2012.

MACEDO, F. L. O. Arquitetura da informação: aspectos epistemológicos, científicos e práticos. 2005. Dissertação (Mestrado). Departamento de Ciência da Informação e Documentação da Universidade de Brasília. Brasília.

MCGEE, J.; PRUSAK, L. Gerenciamento Estratégico da Informação. 24 ed. Rio de Janeiro: Campus, 1994.

MORESI, E (Org.). Metodologia da Pesquisa. Brasília: Universidade Católica de Brasília - UCB, 2003. 108 p.

NEVES, J. L. Pesquisa qualitativa - Características, usos e possibilidades. Caderno de Pesquisas em Administração. São Paulo, v.1, n.3, 1996. Disponível em: <www.ead.fea.usp.br/cad-pesq/arquivos/c03-art06.pdf>. Acesso em 3 dez. 2012.

ROSENFELD, L.; MORVILLE, P. Information Architecture for the World Wide Web. 3. ed. Cambridge: O' Reilly, 2006. 
VICTORINO, M. C.; Organização da Informação para dar Suporte à Arquitetura Orientada a Serviços: Reuso da Informação nas Organizações. 2011. Tese (Doutorado). Faculdade de Ciência da Informação da Universidade de Brasília. Brasília.

VICTORINO, M.C.; BRÄSCHER, M. Organização da informação e do conhecimento, engenharia de software e arquitetura orientada a serviços: uma abordagem holística para o desenvolvimento de sistemas de informação computadorizados.

DataGramaZero - Revista de Ciência da Informação - v. 10, n.3, jun/09.

Disponível em: <http://www.dgz.org.br/jun09/F___art.htm>. Acesso em 30 out. 2012.

\title{
Title
}

Guidelines for a methodology for information modeling

\begin{abstract}
Introduction: Establishes guidelines for the development of a methodology for information modeling at Brazilian Chamber of Deputies, based on theoretical analysis of the elements that make up an information architecture and of information organization, knowledge organization and information management principles.

Objective: To allow the integration, sharing and information organization, contributing effectively to the implementation of an information architecture model within the Brazilian Chamber of Deputies.

Methodology: Literature review and documentary research.

Results: Displays the guidelines for information modeling, applied to the needs and informational practices of the Brazilian Chamber of Deputies.

Conclusions: The information organization is directly related to the information representation, which consists in the information modeling object; that the guidelines proposed in this paper represent a means for the implementation of an information architecture within the Brazilian Chamber of Deputies.
\end{abstract}

Keywords: Information Architecture; Information Organization; Knowledge Organization; Information Management; Information Modeling.

\section{Título}

Directrices para una metodología para modelado de la información

\section{Resumen}

Introducción: Presenta las directrices para el desarrollo de una metodología para el modelado de información en la Cámara de Diputados de Brasil, con base en el análisis teórico de los elementos que conforman una arquitectura de la información y de los 
principios de organización de la información, organización del conocimiento y gestión de la información.

Objetivo: Permitir la integración, compartir y organizar la información, contribuyendo eficazmente a la aplicación de un modelo de arquitectura de la información en la Cámara de Diputados de Brasil.

Metodología: Revisión de la literatura y la investigación documental.

Resultados: Muestra las directrices para el modelado de información, aplicadas a las necesidades y prácticas de información de la Cámara de Diputados de Brasil.

Conclusiones: Se concluye que la organización de la información está directamente relacionada con la representación de la información, que consiste en el objeto del modelado de información; que las directrices propuestas en este documento representan un medio para la implementación de una arquitectura de la información en la Cámara de Diputados de Brasil.

Palabras clave: Arquitectura de la Información; Organización de la Información; Organización del Conocimiento; Gestión de la Información; Modelado de la Información.

Recebido em: 21.08 .2013

Aceito em: 17.02.2015 